\title{
Improving the utility, performance, and durability of wood- and bio-based composites
}

\author{
J.E. Winandy ${ }^{1} \cdot$ J.J. Morrell ${ }^{2}$
}

Received: 26 August 2016 / Accepted: 20 February 2017 / Published online: 9 March 2017

(C) INRA and Springer-Verlag France 2017

\begin{abstract}
- Key message This paper briefly reviews the state of the art in various types of wood- and bio-based composites, summarizes recent advances, and then discusses future possibilities for improving the durability of wood- and bio-based composites.

- Context Wood can be processed and reformed into a number of different biocomposites.

- Aims We aimed at reviewing the state of the art in various types of wood- and bio-based composites.

- Methods Review of utility, performance and durability of wood- and bio-based composites.

- Results The advanced biocomposites will:

Combine wood, natural biofibers, and non-biomaterials to create synergistic hybrid materials that far exceed performance capabilities of current biocomposites

Be renewable, recyclable, and totally sustainable

Provide superior performance and serviceability exceeding performance of current biocomposites

Be more durable, dimensionally stable, moisture proof, and fire resistant

Be less expensive to produce and use (over the life cycle of use) than the materials they replace
\end{abstract}

Handling Editor: Jean-Michel Leban

Contribution of the co-authors: All co-authors wrote the manuscript.

J.E. Winandy

jwinandy@umn.edu

1 Department of Bioproducts and Biosystems Engineering, University of Minnesota, St. Paul, MN, USA

2 Department of Wood Science and Engineering, Oregon State University, Corvallis, OR, USA
- Conclusion The next generation of advanced wood- and biobased composites must provide high-performance construction and specialty products that simultaneously promote resource and environmental sustainability and provide advanced performance, long-term performance, enhanced durability, and value.

Keywords Composites · Wood-based composites · Bio-based composites $\cdot$ Durability $\cdot$ Performance $\cdot$ Moisture issues

\section{Introduction}

Wood can be processed and reformed into a number of different configurations and/or combined with a variety of materials to address unique engineering challenges (Figs. 1 and 2). Wood-based composites present a dizzying array of possibilities in terms of both structural and aesthetic applications. However, it is important to remember that the wood within these composites is often unchanged from its native state and therefore has many of the same thermal, physical, and biological properties it had in the original log or board. These properties include hygroscopicity, an associated tendency to swell as moisture content increases to the fiber saturation point and a susceptibility to biological attack at the same moisture level. Moisture and degradation are inextricably linked with wood use, especially in composites.

Wood-water relationships are related to element size Wood composites are often made from various types of wood elements, such as fibers, chips, flakes, strands, particles, or veneers (Fig. 3). Wood elements in a composite tend to be small relative to most solid wood products, with a larger surface-to-volume ratio. Moisture absorption by wood materials is directly related to the exposed surface area and tends to 
Fig. 1 Classification of wood composite panels by particle size, density, and process (Suchsland and Woodson 1987)

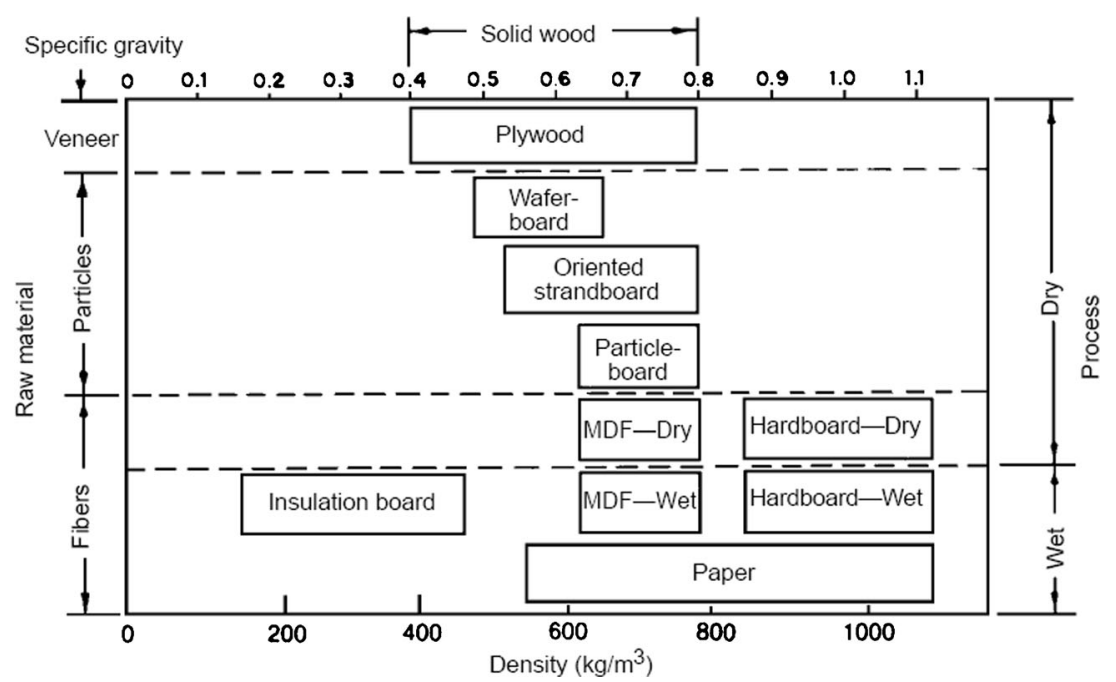

be dominated by exposed end-grain area. The smaller wood elements comprising the base substrate of virtually all wood composites are more likely to absorb moisture to a greater degree than solid wood.

Wood is naturally hygroscopic and its moisture content will vary with temperature and relative humidity as well as with external liquid wetting. Wood in most structures should reach an equilibrium moisture content between $12 \%$ and $19 \%$ moisture content under typical interior applications; however, moisture content can cycle in a wood product with relatively little effect on long-term performance as long as it remains below the fiber saturation point most of the time. In most cases, wood in a composite material retains many of its inherent moisture behavior properties; however, many factors contribute to fundamental differences in how and to what degree wood moisture relationships differ between composite materials and solid wood (Table 1). Two of the most important critical issues will now be specifically discussed.

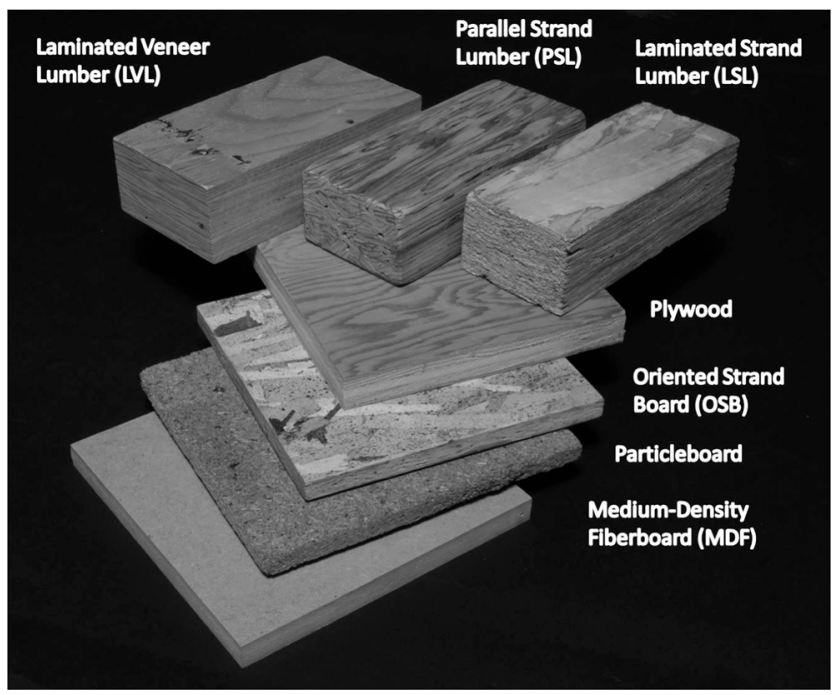

Fig. 2 Examples of various composite products (clockwise from top left: LVL, PSL, LSL, plywood, OSB, particleboard, and fiberboard)
Adhesive resin effects Some proportions of the wood material in a composite are penetrated by the resin system, making that part of the system more hydrophobic than normal wood materials. In such cases, the wood material often contains cured resin in the cell lumens and in some cases in the actual wood cell wall. In such cases, that proportion of wood material containing cured resin is constrained from absorbing moisture. There are a multitude of resin systems; each has unique chemistry, process applications, economics, and endproduct performance. This explains why some resin systems are most common in one type of wood composite type and not others. A comprehensive discussion of the unique characteristics of each resin system relative to composite durability is beyond the scope of this chapter. But, it is generally accepted that the more water-resistant the bonded resin system becomes and the more deeply and effectively that resin system penetrates or encapsulates the wood cell wall, the more durable that wood composite product becomes.

Processing effects Each wood composite system (Figs. 1 and 2) has a unique manufacturing process involving wood component processing, adhesive-wood blending, additives, composite formation (e.g., layup, consolidation, and curing), and post-manufacturing preparation. Further, each process has multiple subprocesses and uses various equipment types that can enhance or modify the engineering, durability, or aesthetics of that wood composite product. While a comprehensive review of the relationships between processing and composite durability is beyond the scope of this paper, it is a common belief that composite durability is strongly related to achieving good bonding between wood elements and/or enhanced moisture resistance or exclusion. Traditionally, process equipment improvements concentrated on improving the process efficiency and reducing energy consumption. Two critical issues are closely related to the manufacturing costs. More recently, there has been rapid development and 
Fig. 3 Basic wood elements, from largest to smallest (Kretschmann et al. 2007)

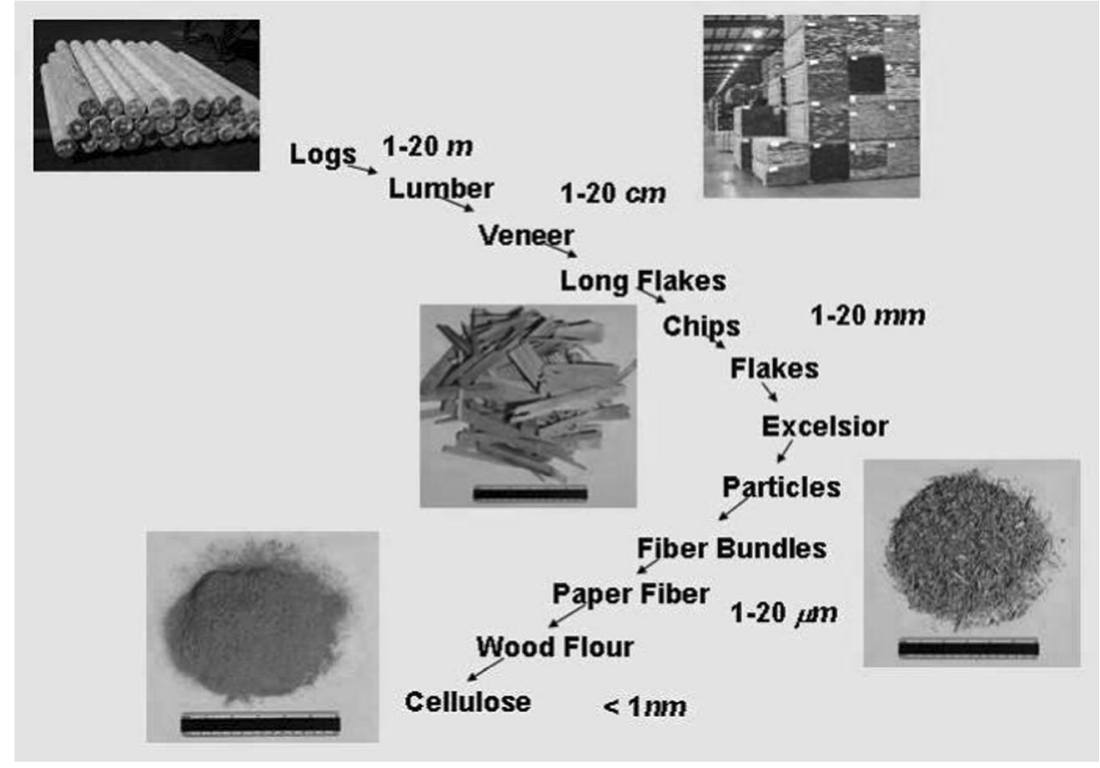

advances in sensors for process control and product quality. Some examples of sensor evolution include the medium-density fiberboard (MDF) blow detector from about 15 years ago, online moisture meters, and dynamic monitoring of resin curing. From an equipment standpoint, blowline technology for MDF was a mature technology. With blowline technology, MDF manufacturer's experienced about $2 \%$ to $3 \%$ resin loss due to its pre-curing problems. On the other hand, its advantages were uniform resin coverage and a simple operating process. Recently, mechanical blending has been introduced to MDF with the goal being reduced resin consumption, but the resin coverage (i.e., resin spots) and MDF surface quality

Table 1 Critical issues to recognize when considering differential durability between wood and natural fiber composite products to that of solid wood

Increased potential for moisture-induced swelling:

Composites have increased moisture absorptions because of the higher surface-to-volume ratios of fibers-particles-strands-veneers than solid wood

When exposed to moisture, most wood or natural fiber composites experience some level of thickness relaxation related to release of compressive stresses induced during hot pressing

Increased quantities of void space in the interior of composites

Increase expose of fibers-particles-strands-veneers to fungal spores during composite manufacturing and processing resulting in potential for more rapid fungal incubation when the composite product is exposed to water or when wet

Critical benefits and shortcomings of the adhesive resin systems and water-repellant additives (such as waxes) being considered

Potential for chemical interaction of other additives such as biocides and flame-retarding agents with the resin-wax system being considered

Potential for thermal degradation of fibers-particles-strands-veneers during composite manufacturing and processing and its effects on resin-wax-biocide relationships issues continue to present processing challenges to uniform performance and surface quality.

\section{Background}

Virtually all levels of moisture intrusion in a wood-based composite can profoundly affect wood properties (USDA 2010). Swelling of wood as it sorbs moisture can disrupt the bonds between individual particles or layers, leading to unrecoverable swelling due to release of compressive stress imparted in hot pressing. This results in increased void space within the composite and permanent negative effects on both composite performance and durability. For example, flexural properties of oriented strandboard or plywood both declined significantly with relatively short rainfall exposures as the panels swelled and shrank under conditions that might occur during construction (Meza et al. 2013). Although liquid water intrusion has obvious detrimental effects, even cyclic exposure to varying high than low relative humidities can negatively impact properties (Moya et al. 2009). Exposing laboratory-manufactured flakeboard to as few as three cycles of $90 \%$ relative humidity (RH) for 4 weeks followed by $30 \% \mathrm{RH}$ for 4 weeks caused noticeable changes in both equilibrium moisture content and thickness swelling. Equilibrium moisture content increased from $3 \%$ to $5 \%$ after three wet/dry cycles, while thickness swelling increased from $10.5 \%$ to $14 \%$ over the same exposure. The need for enhanced resistance to both moisture uptake and subsequent biological attack has long been recognized (Schmidt et al. 1983), and development of such systems has been extensively reviewed (Kilpatrick and Barnes 2006; Gardner et al. 2003; Morrell et al. 2012; Smith and Wu 2005).

The potential impacts of moisture cycling on physical properties even extend to wood/plastic composites. 
Although the interactions between hydrophilic wood and the hydrophobic plastic are limited, wet/dry cycles apparently disrupt even this limited interaction, producing significant losses in bending strength (Silva et al. 2007). The degree of damage in any wood-based composite depends on a number of factors including the particle geometry, the quality of resin bonding, the presence of waxes or other water repellents, the degree of swelling of the wood, and the inherent resistance of a given wood species to water uptake.

Another consequence of repeated cyclic wetting is biological deterioration, although this often requires longer time periods before any damage becomes evident. Most organisms that degrade wood require free water to be present in the wood, and this usually occurs when moisture contents exceed $30 \%$. Wood-based composites are generally intended for interior uses where the moisture content would only approach that level if there was a leak or if elevated relative humidity led to condensation. Many composite manufacturers categorically state that their products are only intended for interior uses in an attempt to limit the potential for exposure to conditions that would be conducive to biological attack. However, construction is an imperfect practice and designs do not always succeed in excluding moisture. As a result, moisture levels in portions of many buildings do reach conditions where biological attack is possible and this can result in substantial repair costs.

Moisture development in buildings can be insidious. As a quick example, consider a 2400 -square foot house which has approximately 16,000 board feet of softwood lumber. That lumber weighs approximately $17,156 \mathrm{~kg}$ when oven dry. The house also contains 14,000 square feet of composite panel products that weigh approximately $13,608 \mathrm{~kg}$ when oven dried. If we assume that the house equilibrated to $14 \%$ moisture content after construction, then that $30,764 \mathrm{~kg}$ of wood contains $4307 \mathrm{~kg}$ of water. Once the house is built, the inhabitants create an average of $4.81 \mathrm{~kg}$ of water/day (mostly through respiration), taking 3 showers adds $0.68 \mathrm{~kg} /$ day, cooking $0.54 \mathrm{~kg} /$ day, and dishwashing approximately $0.32 \mathrm{~kg}$ /day. The overall water input in our house is $6.35 \mathrm{~kg} /$ day. Designing structures to help this water escape is critical for limiting the risk of decay, but if even $20 \%$ of the water is retained in a building, in 5 years, the house will have gained $2315 \mathrm{~kg}$ of water and the average wood moisture content will be $21 \%$. This moisture, however, is unlikely to be evenly distributed. Instead, moisture will tend to condense on cold surfaces and accumulate in these zones to create conditions suitable for both physical and biological degradation. Thus, while manufacturers insist that many composites are intended for dry uses, moisture intrusion is always a risk and needs to be considered wherever wood is used.

The mechanisms and risks of wetting and deterioration in various types of wood-based composites must first be understood before developing methods for preventing damage, remediating deterioration once it occurs, and restoring capacity of a composite building element after the moisture problem has been solved.

\section{Discussion}

Wood-based composites can take a variety of forms from simple glued laminated beams to complete composites composed of multiple materials in complex orientations designed to optimize the best properties of each component. These materials have dramatically different engineering performance. A comparative review of the unique mechanical and engineering properties of each various wood composite type is given in chapter 12 of the USDA Wood Handbook (2010). This paper will focus on varying moisture relationships and their influence on durability of each composite type. It is most useful to assess each separately.

Laminated beams At its simplest, the laminated beam is a highly useful composite that allows for the production of much larger elements from smaller dimension lumber. The beam is still largely wood, and it will experience many of the same problems as the parent boards. Laminated beams are generally used indoors where they are protected from wetting, but many architects like the aesthetics of these beams and have long exposed them outdoors. As a result, the ends of the beams trap moisture, which leads to decay and premature replacement. Capping the upper surfaces and ends of the exposed beams can reduce this risk, but it is far more prudent to treat the beam with preservatives prior to installation.

Beams can either be fabricated using preservative-treated lumber or treated after layup. Treatment prior to layup will produce a more thoroughly protected beam, but it also creates issues related to the tendency of some preservatives to interfere with gluing. Pretreatment before laminating also creates the need to plane the pretreated lam stock to its final dimensions prior to layup. Planing also removes some of the preservative treatment, reducing the effectiveness of the treatment barrier (especially in beams constructed using thinner sapwood species), and results in the production of preservativetreated planer shavings that can pose a disposal challenge. As a result, very few beams are fabricated using treated lumber.

When enhanced durability is required, laminated beams, poles, and posts are most often pressure treated after gluing. Post-gluing treatment has been shown to produce excellent performance in laminated utility poles, and this can be directly related to the fact that the beams are dry prior to treatment and therefore do not have to dry in service. Conventional round utility poles are normally treated, while their interiors are still above the ultimate in-service moisture level (AWPA 2016). These poles then dry in service and the stresses that build up during drying result in the development of deep checks that 
can penetrate beyond the depth of the original preservative treatment. This allows liquid water and decay fungi to enter the untreated wood inside, leading to internal decay and potentially reduced service life. This checking is less likely to occur in laminated poles treated with oil-based preservatives. The APA-The Engineered Wood Association recommends that beams only be treated using oil-borne preservative systems because of concerns that treatment with water-based systems will result in excessive swelling, followed by later checking as the beams dry and may also weaken adhesive bonds. Full-scale testing of Douglas-fir beams treated with either ammoniacal copper zinc arsenate or disodium octaborate tetrahydrate showed that treatment had no negative effects on flexural properties and only a marginal effect on checking (Long and Morrell 2012; Vaughn and Morrell 2012). Post-layup treatments with waterborne preservatives can result in check development, but the risk is relatively low in thin sapwood species because the treatment (and therefore the water intrusion depth) is relatively shallow. Thus, the risk of uneven stress development as the wood dries will be lower than in green solid wood. The resulting treated beams can also be painted or stained to be more aesthetically pleasing.

Structural composite panels A structural composite panel (SCP) is a commonly accepted term for an array of panel products used in structural applications (to distinguish them from panels that are primarily decorative in nature). In North America, the performance properties of SCP are defined in ANSI Standard PS-2-10 (APA 2014). Structural plywood and oriented strandboard (OSB) are the two primary panel types in this category. For the purposes of this discussion, laminated veneer lumber (LVL), which differs from plywood in veneer orientation, will also be discussed because of the similarities in deterioration risk.

Plywood/LVL Like laminated beams, plywood and LVL have high wood/resin ratios that make them perform more like solid wood; however, there are some important differences. One aspect of these products that can affect performance is that both plywood and LVL are made using thin rotary-peeled veneers, not the thicker, lumber-like lam stock used in glulam. Another critical difference in plywood and LVL is that rotarycut veneers experience lathe checks from the rotary-knife cutting procedure. These lathe checks increase the surface-tovolume ratio of veneer compared to solid wood. A final difference is the type(s) and amount of resin. Resin acts as a barrier between layers, and these resin-impregnated layers are generally less likely to be attacked by fungi and insects. Resin can also more easily and more deeply penetrate into the thinner veneers, especially in the area surrounding the lathe checks. To a limited extent, this deep penetration of resin into the veneers and much higher amounts of resin used can result in enhanced performance both through reduced water uptake and decreased fungal attack. Elevated resin content is often related to both moisture resistance and physical durability. Alternatively, increasing resin content also sharply increases panel cost. For example, marine grade plywood can contain up to $10 \%$ resin and this large amount of resin markedly improves the resistance of this material to fungal attack. While wood species can also affect performance, this species-related effect would be no different than would be found with the original wood. Laminated veneer lumber differs in veneer orientation but is otherwise similar to plywood in terms of resin content and should perform similarly in service. Both materials will tend to swell when wetted and beyond a point this can lead to permanent, unacceptable deformation.

The durability of both plywood and LVL can be enhanced by preservative treatment. Plywood has long been pressuretreated with preservatives and fire retardant (FR) chemicals for a variety of applications. The lathe checks in the rotarypeeled veneers facilitate preservative or FR penetration, and there is ample evidence that plywood panels with incomplete penetration still perform well in service (Fahlstrom 1982; Miller and Currier 1984; Smith and Balcaen 1978; Wang et al. 2005). Preservative-treated plywood has been used for over 40 years as an important component of the Permanent Wood Foundation with no reports of failures. FR-treated plywood has been used for decades as roof sheathing in multifamily and non-residential construction. LVL can be similarly pressure treated with preservatives, and this material is commonly treated with light organic solvent-borne preservatives for use in tropical environments, like Hawaii, where the risk of termite attack is extremely high.

An alternative to pressure treatment is to use a glue line additive. This approach is typically limited to applications where the risk of wetting is limited, but termite attack can occur. Insecticides such as bifenthrin or imidacloprid are added to the resin prior to layup and create a potent barrier against termite attack. One problem with glue line additives is the tendency of the insecticides to degrade in the resin due to the high $\mathrm{pH}$ of the resin system coupled with the elevated temperatures used in pressing. Accordingly, manufacturers typically add additional insecticide to the resin to account for this degradation and to eventually leave a sufficient amount of active biocide in the finished product. There have also been recent moves to incorporate fungicides into resins for LVL for aboveground exterior exposure, although these products can only use a limited range of veneer thicknesses since the fungicide must be able to migrate from the resin and into the surrounding veneers during pressing.

Oriented Strandboard/Flakeboard OSB production in North America is now estimated to exceed structural plywood by nearly $2: 1$. OSB is manufactured with thin wood strands cut by a rotating series of knives and generally with 
thicknesses of $<0.25 \mathrm{~mm}$. Flakeboard is an older term for similar strand or flake-based composite panels, but it was not designed or intended to be as reliable a structural panel as is OSB. Two differences are commonly accepted to differentiate these two "generations" of panels. OSB is manufactured with strands that generally have a length-towidth ratio $\geq 4-8: 1$, whereas flakes usually have a length-towidth ratio $\leq 2-4: 1$. OSB is a layered wood composite composed of dried and graded strands that are coated or sprayed with a moisture-resistant thermoset adhesive. These strands are laid up on both face layers such that the long strands are laid parallel to the length of the intended panel, often formed into three-layer thick panels and hot-pressed to finished thickness. Common structural panel thicknesses for OSB vary from 9 to $28 \mathrm{~mm}$; common panel sizes are 1.2 by $2.4 \mathrm{~m}$ ( 4 by $8 \mathrm{ft}$ ), but longer and wider panels are becoming more commonly produced as a result of consumer demand. Flakeboard panels usually do not have long, oriented strands and are not often formed as layered mats. The oriented, layered mats confer directional properties to OSB panels that make them suitable for use as exterior sheathing. Flakeboards may look like OSB but do not have nearly the same structural performance and reliability.

OSB and flakeboard are typically manufactured from lower density, easily compressible woods such as aspen, yellow poplar, sweetgum, and an array of softwood species. Waxes and other additives may be included during manufacturing, but the wood species employed in these panel products usually have little or no resistance to biological degradation.

The thousands of wood strands or flakes used to manufacture a single OSB or flakeboard panel have collectively a much greater total surface-to-volume ratio than do the veneers used in plywood or LVL. The far greater end-grain surface areas render OSB and flakeboard products more prone to experience swelling issues than plywood when exposed to either liquid moisture or elevated humidities while in-service. This moisture exposure, especially reoccurring cyclic moisture exposure, leads to permanent swelling of wood strands that disrupts the original wood/resin interface (i.e., bonding). This loss in bonding sharply reduces panel properties. Additional wax and resin can be added to the furnish prior to pressing to reduce moisture uptake and this is sometimes done for products such as underlayment for floors, but even these products will eventually swell with prolonged moisture exposure.

Most OSB or flakeboard cannot be treated after manufacture using traditional pressurized preservative or fire retardant treatments because the treatment will induce unacceptable swelling and, hence, disruption of the wood/resin bonds. This is particularly true with water-based systems because they release the compressive set imparted during hot pressing and resin curing, producing associated losses in panel structural properties. The use of light-solvent treatments that impart minimal color change and volatilize from the wood after treatment might be plausible, but the potential for surface residues and post-treatment blooming usually prevents acceptance of such treatments. These solvent processes also tend to be more costly. They are, however, used for treating composite assemblies such as I-joists, employed in high termite hazard areas.

The most commonly accepted alternative to pressure impregnation is to treat wood strands after stranding but prior to drying, resin application, mat formation, and hot pressing. While this seems to be a straightforward concept, the process requires a holistic and fundamental understanding of the resin and preservative/fire retardant chemistries. To optimize structural performance and durability, control of each resin system's unique curing processes and its potential for chemical interactions with each subcomponent of the preservative or fire retardant chemical system is required. Resin curing rates can be markedly altered by the presence of preservatives (Kreber et al. 1993). A number of adhesive resin-preservative systems have been studied (Gardner et al. 2003; Kilpatrick and Barnes 2006; Schmidt et al. 1983; Murphy et al. 1993; Ross et al. 2003; Vidrine et al. 2008). Poor resin selection can result in either incomplete curing or excessively fast curing that results in poor penetration into the wood cells. Tailoring resins for use with preservative treated flakes or strands is the subject of considerable interest as panel manufacturers seek to move their materials into markets where biological attack is possible. The other limitation of pretreatment is the added steps involved in drying, treating, and then possible redrying of strands/flakes prior to resin application and further panel processing.

The more attractive alternative to pressure impregnation or flake pretreatment is to add powdered materials to the resin/ wood mixture prior to pressing. This process is commonly used to add zinc borates to OSB or medium-density fiberboard for exposures where termite attack is possible. Zinc borate has low water solubility, making the boron less likely to interfere with curing, and the resulting panels have been shown to perform well under severe termite exposures (Kilpatrick and Barnes 2006; Lake and McIntyre 2006; Ayrilmis et al. 2005). Nano- and micro-sized elemental copper are another option for enhancing composite durability since they appear to have limited potential for resin-preservative interactions.

A new ASTM Standard D7857 for assessing the effects of adding preservatives or FR chemicals to strand-based composites like OSB has recently been adopted (ASTM 2016) that evaluates resin compatibility with preservatives or FR chemicals as well as the processes used to apply those chemicals with the adhesive resins. The new standard then employs recognized accelerated aging procedures to assess the structural effects of various additives on properties. Products such as these may create new markets for fire resistant composites and/or highly durable composites. 
Structural composite lumber Structural composite lumber (SCL) is the commonly accepted term for a group of structural lumber-like products manufactured with varying types of peeled wood veneer sheets, strands of peeled clipped veneer, or thin strands or flakes. Strands and flakes are similar in that they are traditionally cut by a rotating series of knives to thicknesses $<0.25 \mathrm{~mm}$ but differ in that strands often have a length-to-width ratio $\geq 4-8: 1$, whereas flakes have a length-towidth ratio $\leq 4: 1$. The most recognized varieties of SCL include (1) LVL, (2) parallel strand lumber (PSL), (3) laminated strand lumber (LSL), and (4) oriented strand lumber (OSL). Each type of SCL is different, but each has common attributes. As a group, each SCL is a layered wood composite composed of dried and graded wood elements that depending on the type of SCL can include veneers, strands, or flakes. All are coated or sprayed with a moisture-resistant adhesive, formed into thick billets or panels, then after hot pressing to finished thickness the billets or panels are resawn into specified SCL sizes. In each type of SCL, the individual layers of veneer, strand, or flakes are oriented so that their grain runs primarily in the same direction. The resulting products outperform conventional lumber when either face- or edge-loaded because the majority of wood fibers are aligned and, as with most composites, because the defects are distributed throughout the material. SCL is a uniform engineered wood product with highly predictable mechanical properties and is usually considered to be virtually free from warping and splitting when kept dry. Typical uses for SCL include beams, joists, studs, columns, rafters, headers, and I-joist flange material. Multiple pieces of SCL are often glued or nailed together to form 89-133-mmthick (3-1/2- to 5-1/4-in.thick) headers or columns in critical $38-\times 89-\mathrm{mm}$ (nom. 2 by 4 ) or $38-\times 133-\mathrm{mm}$ (nom. 2 by 6 ) framed walls).

SCL products can be manufactured using a variety of wood species and, as expected, durability will vary depending on the inherent durability of the parent wood. These products present a further challenge in terms of wetting because the parent materials are veneer sheets or clipped strands and the resulting composites have numerous pathways for moisture intrusion.

On the positive side for LVL and PSL, the lathe checks in the veneer and gaps between individual clipped veneer elements also allow pressurized preservative and fire retardant treatment to deeply penetrate the composite and have been successfully used to increase composite durability of LVL and PSL. This makes preservative treatment relatively easy, and a number of preservatives are standardized for pressure treatment of PSL and LVL (AWPA 2016a). The primary disadvantage of pressure treating LVL and PSL with water-based preservatives is excessive liquid absorption leading to possible swelling and compressive-stress relaxation.

LSL and OSL are made from thin strands of wood similar to those used for structural composite panels. LSL and OSL are typically manufactured with much higher adhesive resin loadings than are commonly used with OSB panels. Previous discussions on structural composite panels related to the requirement for pretreating the strands after stranding but prior to drying, resin application, and hot pressing also apply to a slightly lesser degree to LSL and OSL mainly due to increased resin loadings.

While the mechanical properties of the four types of SCL are relatively similar, their resistance to moisture differs significantly. LVL and PSL are manufactured using rotary-peeled veneers. The relative in-service performance when exposed to liquid wetting or high relative humidity is similar to plywood. LSL and OSL are manufactured from strands and accordingly have a higher surface-to-volume ratio of end-grain. They are often considered to be more sensitive to moisture absorption and dimensional swelling than LVL or PSL. LSL and OSL are more similar to OSB in composition and moisture behavior, while the moisture relationships of LVL and PSL are more similar to those of plywood.

Particleboards/fiberboards Particleboard and fiberboard are commonly considered nonstructural panels. In North America, the performance properties of SCP like particleboard are defined in ANSI Standard A208.1 (ANSI 2009a), while those for fiberboards are defined in ANSI Standard A208.2 (ANSI 2009b). Particleboards are manufactured from ground wood of varying sizes but with no distinct differentiation in length, width, or thickness. They generally use less moisture-resistant urea formaldehyde (UF) resins that limit their application to dry uses. Wax additives are usually added to improve resistance to moisture ingress, but these particle- or fiber-based products will swell substantially under prolonged moisture exposure. These materials are rarely treated with any preservative, but fire resistant particleboards are produced by adding borate to the furnish prior to pressing. The levels of boron required for fire protection would invariably also render this material resistant to fungal and insect attack. As with other composite systems, care must be taken to formulate the resin to account for the possible effects of the boron on resin curing.

Fiberboards are most often manufactured by cooking wood chips in a wet, hot environment (often steam-heated) under pressure. The wood chips explode into wood fibers when the pressure is rapidly released. These particles or fibers are dried and sprayed with an adhesive prior to pressing. Increasing resin content can improve durability but it also increases costs. It is possible to add a variety of other materials, including preservatives or water repellents to the mixtures prior to pressing. As with particleboards, fiberboards are not reliably waterresistant and should not be used in adverse in-service environments where wetting is likely.

Fibers and, to a lesser extent, particles have surface-tovolume ratios many times higher than strands. Accordingly, the moisture resistance of fiberboard and particleboards is generally considered lower than OSB and far lower than 
plywood. This reduced moisture resistance is due to the larger proportion of end-grain due to the higher surface-to-volume ratio of the fibers and particles and because of their use of resin systems, such as UF, that have far lower moisture resistance than the phenol formaldehyde (PF) and isocyanate-based (pMDI) resins used in structural panels like OSB and plywood. However, new technologies related to thermal or chemical modification of fiber altering moisture absorption relationships may produce significant improvements in fiberboard performance and durability.

Several types of FR-treated MDF and/or particleboard composites are commercially manufactured. Many MDF and/or particleboard composites use UF resins as an adhesive binder. The $\mathrm{pH}$ and resin chemistry of many UF resins are compatible with FR chemical additives. UF resin/FR compatibility has resulted in the development of a variety of FRtreated MDF and/or particleboard composites. However, UF resins provide little resistance to moisture when exposed inservice and the resulting panels have poor wet-service performance and eventually suffer deterioration in resin bonding and loss of structural integrity.

\section{Natural fiber-plastic and wood-inorganic composites} Wood-plastic or natural fiber-plastic composites (NFPCs) are gaining in popularity because of their perceived advantages in water resistance, ability to use recycled materials, and high performance-to-manufactured cost ratio.

NFPCs are differentiated from previously discussed biocomposites in that NFPCs employ a thermoplastic adhesive system rather than thermoset adhesive systems. NFPCs were initially developed as a pathway to use recycled wood and recycled plastic, but the first attempts were not very successful. One of the important original assumptions with NFPCs was that the plastic would completely encapsulate the wood particles, thereby protecting them from wetting and decay (Schmidt 1993; Morris and Cooper 1998; Verhey et al. 2001; Schauwecker et al. 2006). Wood in NFPCs serves several purposes. It is an inexpensive filler that makes the resulting boards less dense and easier to work with. Wood also adds stiffness to the NFPC. The assumption that the wood was encapsulated proved to be incorrect, although these materials clearly wet much more slowly than other wood-based composites (Wang and Morrell 2004). As a result, the wood in NFPCs was found to be susceptible to fungal attack (Mankowski and Morrell 2000). The addition of zinc borate was found to be a simple solution that was compatible with the manufacturing process. Since that time, additional materials have been added to NFPCs to enhance resistance to ultraviolet light and avoid certain discoloring reactions that can mar the NFPC surface. A number of reviews on the durability of wood-plastic composites exist (Morrell et al. 2010; Laks et al. 2010). Addition of borates or possibly nano- or micro- sized elemental copper could enhance biological durability of NFPC.

NFPCs also have potential advantages when used as roof cladding materials. NFPC roof cladding would have low process costs and promote enhanced recycling opportunities for repurposed plastics and renewable bio-based fibers. Studies of roof temperatures using NFPC roof shingles found that attic air temperatures in warm climates were significantly cooler than in similarly constructed structures using traditional North American fiberglass/asphaltic roof shingles (Winandy et al. 2000).

Wood-inorganic composites (WICs) are composed of inorganic binders, such as cement, ceramic, or metal phosphate salts, along with various cellulosic fibers (Jorge et al. 2004). Wood is the most common fiber employed in North America and is used to reduce weight of the finished product, decrease cost, and improve flexural properties. WICs employ an ambient temperature setting binder system using cementateous- or ceramic-based binder systems. The curing process of the WIC binder systems is irreversible. The use of cement normally produces a high $\mathrm{pH}$ environment that would be hostile to many wood-degrading organisms provided the wood/cement ratio is sufficient to produce encapsulation. Initial attempts to produce wood/cement shingles experienced difficulties because high proportions of wood were used to reduce weight on the roof. As a result, the wood remained exposed and susceptible to wetting and biological attack, producing early failures and shortened service life. More recently developed products use lower levels of wood and improved processing, resulting in better fiber encapsulation.

The recent success of WIC product is, in part, due to the failure of wood strand-based composite siding in the 1980s. At that time, various failures in terms of manufacturing and installation of some commercial OSB siding (i.e., cladding) products resulted in massive failure and lawsuits. The market shifted away from wood composite siding and towards various wood/cement products. In this case, the wood fibers appear to be well encapsulated by cement and the high $\mathrm{pH}$ of the system provides further protection against biological attack. Ongoing laboratory decay tests by Morrell and Freitag at Oregon State University have indicated that traditional decay fungi have little or no effect on these siding materials thought to be due to the adverse $\mathrm{pH}$ conditions of WIC.

In 2014, 1.2 million new single family homes and 0.3 million new multifamily homes were built in the USA which required durable roofing and siding (US Census Bureau 2014). Over $25 \%$ of new homes have decks built when first constructed, and another $25 \%$ are estimated to have decks added within 5 years (Smith and Bailey 2003). Growth of NFPC over wood decking in the last 20 years is partially due to public perception for greater durability 
and reduced maintenance of NFPC. Wood-inorganic composites provide siding and roof products that would be much more resistant to impact damage, fire, insects, and biological decay than many other siding products. From 1995 to 2005 to 2014 , the WIC siding market grew from $<1 \%$ to $9 \%$ to $18 \%$, respectively (US Census Bureau 2015). New advanced WICs may result in additional market growth if they can significantly reduce weight and further enhance durability.

Assemblies and systems (I joints, shear walls, etc.) An increasing array of composites are used in assemblies that may include several different types of composites coupled with solid wood. The best example of such a product is the I-joist, which utilizes an OSB web and either solid wood or LVL flanges. These products are typically used as floor joists in dry use applications, but they can become wetted either during construction or afterwards as a result of leaks and condensation. Field exposure of I-joists composed of OSB webs and LVL flanges revealed that assemblies gradually experienced losses in flexural properties, but the effects were not rapid (King et al. 2015). The most interesting effect was an increase in variability. Composite materials typically have lower coefficients of variation that allow engineers to design more tightly. However, moisture intrusion sometimes reduces the ability to take advantage of composite uniformity increasing the importance of internal moisture control in buildings.

Shear walls and shear platforms (e.g., floor systems) are well-known examples of critical composite-based systems. Structural composite panels are also used as sheathing in exterior shear walls. Shear walls and platforms serve critical functions in structures prone to high wind loading or earthquakes. Exposure to moisture and fungal attack could be detrimental to performance if not controlled. Kent et al. (2004a, b, 2005, 2006) showed that the OSB in OSB/Douglas-fir stud assemblies experienced considerable fungal attack under controlled incubation conditions, but the effects of this damage on cyclic loading properties of the shear wall assembly were not immediately impacted. The primary difficulty in these types of studies has been creating conditions suitable for fungal attack on larger assemblies. It is relatively easy to introduce large amount of fungal inoculum to a small assembly under controlled environmental conditions (temperature and moisture). However, those are not the environmental conditions present in many large structures. Building spaces are characterized by widely varying moisture conditions as well as a much more restricted fungal flora. This makes it much more difficult to predict the risk of decay under these conditions, although practical field experience indicates that decay is a common problem in composites. There is a critical need to develop better data on the rates of moisture intrusion into composites, the effects of this moisture on physical properties, and the rate at which fungi invade and cause more substantial effects on composites and composite assemblies.

Another recent development is the ever-increasing building code acceptance across the globe of mass timber buildings. Mass timber buildings use a recently developed wood composite-based system called cross-laminated timber (CLT). CLT panels use multiple layers of kiln-dried lumber laid up in alternating directions, then bonded with structural adhesives to form large panels. CLT panels usually have an odd number of laminations (often three to seven layers). Some experts have referred to CLT as structural plywood using lumber rather than veneer. The CLT panels are cut to size with precut door and window openings in the mill. Entire wall or floor systems are then shipped directly to the job site. These CLT panels are exceptionally stiff, strong, and dimensionally stable. The acceptance and popularity of mass timber building are dependent on composite products like CLT and LVL, and understanding how these products will behave under elevated moisture conditions will be critical for ensuring continued success of the building system.

\section{Non-chemical protection}

While preservatives are the most commonly used method for protecting wood-based composites, nonchemical methods may be suitable for some applications. For example, acetylation can be used to enhance moisture resistance of wood prior to composite manufacturing. The resulting composite should be similarly moisture resistant, and this resistance should also reduce the risk of fungal attack. The process adds cost and might affect bonding of some composites, but it represents one of the more viable non-biocidal methods for protecting wood. Thermal modification has also been proposed for protecting wood above the groundline. The process purportedly decreases the availability of carbohydrate compounds, thereby reducing the risk of fungal attack. Thermal modification also reduces flexural properties, and its possible effects on wood/resin bonds remains unknown. The public desire for reduced chemical usage will likely encourage further exploration of these alternative strategies for wood-based composites. The American Wood Protection Association recently approved guidelines for developing data to standardize both thermally modified wood, non-biocidal chemically modified wood, and wood/natural fiber polymer-bonded composites for the North American market (AWPA 2016b, c).

\section{Nanoparticles to augment biocomposites}

Dimensions of nanoparticles are magnitudes smaller than more conventional constituents of composites. Additionally, 
nanoparticles have characteristics such as very large surface areas, large number densities of particles, and low percolation thresholds that are orders of magnitude different from more conventional materials. Consequently, they can often interact with other components in entirely new ways. As a result, these nanoparticles can be understood and used to enhance bonding, moisture resistance, and/or structural performance, and they may yield unique behavior in biocomposite materials. Nanoparticles have already been shown to improve barrier properties, impart UV resistance without reducing clarity, act as delivery systems for controlled release of additives, improve flame retardancy, nucleate foams of very fine cell structure, and/or help compatibilize polymer blends in a number of bio-based materials (Sabo et al. 2015).

One classic example of the opportunity of nanoscience presents itself with NFPC. Nanoscience offers the possibility of facilitating enhanced bonding between aromatic hydrocarbons such as those in wood or bio-based natural fibers with aliphatic polymers now used in NFPC. This would reduce the need for petrochemical-based adhesives. Improved structural performance and reliability of NFPCs would significantly enhance the engineering properties and structural and thermal utility of NFPC.

The incorporation of various nanoparticles into advanced wood- and bio-based composites could significantly enhance the performance of existing composites in traditional markets as well as foster the development of new types of composites and markets. Realistic and economically viable opportunities for incorporating nanoparticles in biocomposites are currently being aggressively investigated globally.

\section{Summary}

Wood composite technology is based on breaking woody material down to some smaller element, such as a veneer, particle, flake/strand, or fiber, then reassembling these elements into a lumber- or panel-like product. More recently, new innovative bio-based composite products based on natural fibers, wood-natural fiber hybrids, or hybrid products, such as wood- or natural fiber-plastic composites, have recently become popular. Each of these wood- and/or bio-fiber composite technologies allows user/producers to add considerable value to diverse wood- and bio-fiber feedstocks. Another major advance in engineered wood and biocomposites is in product and performance enhancement. Advanced engineered biocomposites are currently being developed that will simultaneously meet the diverse needs of users for highperformance and economical commodity products. These engineered biocomposites will provide advanced performance, durability, and service life. This paper has reviewed the products and durability issues.

\section{References}

ANSI (2009a) ANSI Standard A208.1: American National Standard for particleboard

ANSI (2009b). ANSI Standard A208.2: American National Standard for fiberboard

APA (2014) Performance standard for wood-based structural panels. APA Tech. Bull. S350. ANSI Standard PS-2-2010

ASTM (2016) ASTM Standard D7857: standard test method to evaluate the effects of FR chemicals on properties of strand-based composites. ASTM book of standards. West Conshohocken, PA.

AWPA (2016a) Standard U-1 and T-1. Standards for pressure treated wood. AWPA book of standards. American Wood Protection Association, Birmingham, AL

AWPA (2016b) Guidance Document L: data requirements of listing chemically modified wood with enhanced durability in AWPA standards. AWPA book of standards. American Wood Protection Association. Birmingham, AL

AWPA (2016c) Guidance Document N: data requirements of listing thermally modified wood with enhanced durability in AWPA standards. AWPA book of standards. American Wood Protection Association. Birmingham, AL

Ayrilmis N, Kartal SN, Laufenberg TL, Winandy JE, White RH (2005) Physical and mechanical properties and fire, decay, and termite resistance of treated oriented strandboard. Forest Prod J 55(5):74-81

Fahlstrom GB (1982) Durability of CCA-B treated plywood having nonconforming penetration patters. Forest Prod J 32(2):51-52

Gardner D, Tascioglu C, Wålinder M (2003) Wood composite protection. In: Goodell B, Nicholas DD, Schultz TP (eds) Wood deterioration and preservation: advances in our changing world. American Chemical Society, Washington, DC

Jorge F, Pereira C, Ferreira J (2004) Wood-cement composites: a review. Holz Roh Werkst 62:370-377

Kent SM, Leichti RJ, Rosowsky DV, Morrell JJ (2004a) Biodeterioration effects on nailed connections. In: Proceedings World Timber Engineering Conference, Helsinki, Finland. June 2004. 6 pages

Kent SM, Leichti RJ, Rosowsky DV, Morrell JJ (2004b) Effects of decay by Postia placenta on the lateral capacity of nailed oriented strandboard sheathing and Douglas-fir framing members. Wood Fiber Sci 36:560-572

Kent SM, Leichti RJ, Rosowsky DV, Morrell JJ (2005) Effects of decay on cyclic properties of nailed connections. J Mater Civ Eng 17(5): 579-585

Kent SM, Leichti RJ, Rosowsky DV, Morrell JJ (2006) Analytical tools to predict changes in properties of oriented strandboard exposed to the fungus Postia placenta. Holzforschung 60:332-338

Kilpatrick J, Barnes HM (2006) Biocide treatments for wood composites - a review. IRG/WP 06-40323. Int'l. Res. Group on Wood Preservation. Stockholm, Sweden

King DT, Sinha A, Morrell JJ (2015) Effect of wetting on performance of small-scale shear walls. Wood Fiber Sci 47(1):74-83

Kreber B, Humphrey PE, Morrell JJ (1993) Effect of polyborate pretreatment on the shear strength development of phenolic resin to Sitka spruce bonds. Holzforschung 47(5):398-402

Kretschmann DE, Winandy JE, Clausen C, Wiemann M, Bergman R, Rowell R, Zerbe J, Beecher J, White R, McKeever D, Howard J (2007) Wood. In: Kirk-Othmer encyclopedia of chemical technology. NY. J. Wiley \& Sons. 60p. (https://www.fpl.fs.fed.us/documnts/ pdf2007/fpl_2007_kretschmann001.pdf).

Lake MA, McIntyre CR (2006) Formosan termite response to weathered borate-treated wood. Proceedings: Wood protection 2006, Forest Products Society, Madison, WI. pp 295-298

Laks P, Richter D, Larkin G, Eskola J (2010) A survey of the biological resistance of commercial WPC decking. In: 10th Pacific Rim Bio- 
Based Composites Symposium, October 5-8, 2010, Banff, Alberta, Canada pp 193-201.

Long B, Morrell JJ (2012) Effects of postlayup borate treatment on appearance and flexural properties of Douglas-fir glued laminated beams. Forest Prod J 63(1):46-48

Mankowski M, Morrell J (2000) Patterns of fungal attack in wood-plastic composites following exposure in a soil block test. Wood Fiber Sci 32:340-345

Meza L, Sinha A, Morrell JJ (2013) Effect of wetting during construction on properties of Douglas-fir plywood and oriented strandboard flooring. Forest Prod J 63(5/6):199-201

Miller DJ, Currier RA (1984) Permeability of glue lines in Douglas-fir plywood by preservative solutions. Forest Prod J 14(7):303-309

Morrell JJ, Stark N, Pendleton D, McDonald A (2010) Durability of wood-plastic composites. In: Tenth International Conference on Wood and Biofiber Plastic Composites and Cellulose Nanocomposites Symposium, May 11-13, Madison, WI. Madison, WI: Forest Products Society

Morrell JJ, Vidrine C, Jin L, Preston AF (2012) Termite resistance of copper-based preservative supplemented aspen strandboards. International Research Group on Wood Protection Document No. IRG/WP/12-30594. Stockholm, Sweden. 8p

Morris P, Cooper P (1998) Recycled plastic/wood composite lumber attacked by fungi. Forest Prod J 48:86-88

Moya L, Tze WTZ, Winandy JE (2009) The effect of cyclic relative humidity changes on moisture content and thickness swelling behavior of oriented strandboards. Wood Fiber Sci 41(4):447-460

Murphy RJ, Dickinson DJ, Turner P, Wickens PJ, Hashim R (1993) Vapor boron treatment of wood composites. In: Proc. IUFRO Symp. on the PWood-Based Composite Products. A.F. Preston, ed. Forest Prod. Soc., Madison, WI. pp. 49-56.

Ross A, Ward H, Smith W (2003) New generation of preservation treatments for wood-based panels and other engineered wood products. In: Proc. 2003 European Panel Products Conference, Wales, UK. 8pp

Sabo R, Elhaijar R, Clemons C, Pillai K (2015) Characterization and processing of nanocellulose thermosetting composites. Chap 15 . In: J.K. Pandey et al. (eds.) Handbook of polymer nanocomposites. Processing, performance and application-volume C: polymer nanocomposites of cellulose nanoparticles. Springer-Verlag. Berlin

Schauwecker C, Morrell J, McDonald A, Fabiyi J (2006) Degradation of a wood-plastic composite exposed under tropical conditions. Forest Prod J 56(11-12):123-129

Schmidt EL (1993) Decay testing and moisture changes for a plastic wood composite. Proc Amer Wood Protection Assoc 89:108-109
Schmidt EL, Hall HJ, Gertejansen RO, Carll CG, DeGroot RC (1983) Biodeterioration and strength reductions in preservative treated aspen waferboard. Forest Prod J 33(11/12):45-53

Silva A, Gartner B, Morrell J (2007) Towards the development of accelerated methods for assessing the durability of wood plastic composites. ASTM J Test Eval 35(3):203-210

Smith B, Bailey D (2003) Emerging domestic markets for treated lumber. Proceedings: Enhancing the durability of lumber and engineered wood products. Forest Products Society, Madison, WI. pp 3-6

Smith RS, Balcaen P (1978) Effect of species composition of preservative treated Douglas-fir plywood on its decay resistance. International Research Group on Wood Preservation Document No. IRG/WP/ 214. Stockholm, Sweden

Smith W, Wu Q (2005) Durability improvement for structural wood composites through chemical treatment. Forest Prod J 55(2):8-17

Suchsland O, Woodson GE (1987) Fiberboard manufacturing practices in the United States. U.S. Department of Agriculture, Ag. Handbook 640. Washington, DC. 26p

U.S. Census Bureau (2014) 2014 characteristics of new housing. U.S. Department of Housing and Urban Development. 763 pg. (http:// www.census.gov/construction/chars/pdf/c25ann2014.pdf).

U.S. Census Bureau (2015) Residential construction in September 2015. U.S. Department Housing and Urban Development. CB15-176. 6 pg. (http://www.census.gov/construction/nrc/pdf/newresconst.pdf).

USDA (2010) Wood handbook: wood as an engineering material. USDA, For. Serv. Gen. Tech. Report FPL-GTR-190, Madison, WI. 508 pgs. (https://www.fpl.fs.fed.us/documnts/fplgtr/fpl_gtr190.pdf).

Vaughn J, Morrell JJ (2012) Effects of post-layup ammoniacal copper zinc arsenate treatment on appearance and flexural properties of Douglas-fir glued laminated beams. European J Wood Products 70:241-244

Verhey S, Laks P, Richter D (2001) Laboratory decay resistance of woodfiber/thermoplastic composites. Forest Prod J 51(9):44-49

Vidrine C, Kamke FA, Morrell JJ, Preston AF (2008) Preserving panels by furnish addition of copper compounds: effects on panel properties. Proc Amer Wood Protection Assoc 104:135-145

Wang W, Morrell J (2004) Water sorption characteristics of two woodplastic composites. Forest Prod J 54:209-212

Wang W, Kent S, Freitag C, Leichti RJ, Morrell JJ (2005) Effect of moisture and fungal exposure on the mechanical properties of hem-fir plywood. J Forestry Research 16(4):299-300

Winandy J, Barnes HM, Hatfield C (2000) Temperatures of wood roof materials and attics in Mississippi and Wisconsin. USDA, For. Serv. Res. Paper FPL-RP-589, Madison, WI. 24p 